\title{
Critical success factors in managing sustainable indigenous businesses in Australia
}

\author{
Kerry Bodle and Mark Brimble \\ Department of Accounting, Finance and Economics, Griffith University, \\ Southport, Australia \\ Scott Weaven \\ Department of Marketing, Griffith University, Southport, Australia \\ Lorelle Frazer \\ Learning and Teaching, Office of the PVC (Business), Griffith University, \\ Southport, Australia, and \\ Levon Blue \\ School of Education and Professional Studies, Griffith University, \\ Mount Gravatt, Australia
}

Sustainable indigenous businesses

Received 24 February 2016 Revised 1 November 2016 7 March 2017 Accepted 18 April 2017

\begin{abstract}
Purpose - The purpose of this paper is to investigate success factors pertinent to the management of indigenous businesses through the identification of points of intervention at the systemic and structural levels. Through this approach, the economic and social values that First Nations communities attach to intangible indigenous cultural heritage (ICH) and indigenous cultural intellectual property (ICIP) may be both
\end{abstract} AQ: 1 recognised and realised as assets.

Design/methodology/approach - This paper adopts a multidisciplinary approach to address a global issue of economic and social significance to First Nation peoples, their businesses and the Australian Aboriginal communities. The authors adopt a First Nation epistemological standpoint that incorporates theoretical perspectives drawn from a diverse range of fields and theories (Preston, 2013), as well as advocate the use of indigenist methodology for research with First Nation peoples as it is underpinned by critical race theory.

Findings - The authors argue conceptually that accounting, accountability and auditing consideration are required to fully identify what is impacting the successful management of indigenous enterprises. Specifically, in relation to accounting, elders should be included to assist in valuing the intangible ICH and ICIP assets. Furthermore, the authors emphasise the need to improve the financial and commercial literacy levels of indigenous entrepreneurs.

Practical implications - The authors prescribe the use of tools for the accounting treatment of ICH and ICIP as intangible assets within an Australian regulatory environment and define an auditing process and accountability model incorporating cultural, social and environmental measures. A central tenet of this model relates to improving levels of personal and commercial financial literacy in the First Nation participants. Collectively, these factors promote informed participation and decision-making, and may promulgate more AQ: 2 sustainable outcomes.

Social implications - Integrated thinking requires all these factors to be considered in a holistic manner, such that a First Nation enterprise and the wider Aboriginal and Torres Strait Islander people can understand, and make decisions based on, the overall impact it has on all their stakeholders and generally on the society, the environment and the economy.

Originality/value - Integrated thinking requires all factors to be considered in a holistic manner, such that a First Nation enterprise and the wider Aboriginal and Torres Strait Islander peoples can understand, and

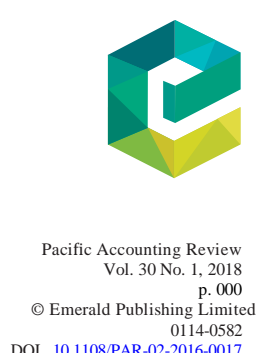


PAR

30,1

2

make decisions based on, the overall impact it has on all their stakeholders and generally on the society, the environment and the economy.

Keywords Indigenous entrepreneurship, Accounting, auditing and accountability, Cultural, Environmental, Social and sustainability values, Financial and commercial literacy, First Nation enterprises, Intangible, Cultural heritage and intellectual property assets

Paper type Conceptual paper

Introduction

Australian First Nation enterprises are underperforming relative to non-indigenous enterprises. The Office of the Registrar of Indigenous Corporations (ORIC) report identified poor management, poor governance and poor financial accounting as key characteristics of failing corporations (Swansson, 2010). A significant recommendation resulting from this study was for "[... .] some explicit treatment of the way in which heritage matters influence (an Indigenous corporation's) management and growth" (Swansson, 2010, p. 37). Central to this recommendation is the contention that attachment to culture and tradition hinders the achievement of mainstream economic goals. Given the maintenance of a strong First Nation culture underpins a number of positive outcomes across a range of socio-economic indicators for First Nation Australians (Altman, 2003), there is support for "culture and heritage to be viewed as part of the solution to Indigenous disadvantage in Australia, and not as part of the problem" (Dockery, 2010, p. 315). Indeed, Gallhofer et al. (2000) asserted that Western values could be transformed for the better by valuing indigenous knowledge. We agree that using accounting techniques in a more inclusive way may increase the success and sustainability of indigenous businesses (Buhr, 2011). In essence, a way forward involves building financial capability of indigenous peoples to have "greater access to and control over the use of government and other funding, and over reporting requirements" (Lombardi and Cooper, 2015, p.96).

The tension between the maintenance of Aboriginal and Torres Strait Islander culture and achievement of socio-economic "equity" can be best considered as a function of "selfdetermination" versus "assimilation" (Dockery, 2010). Until the Aboriginal and Torres Strait Islander knowledge is incorporated into the social and economic structures that help perpetrate inequities, self-determination will not be realised and white privilege and supremacy will continue to be reinforced (Brayboy, 2005; Battiste, 2013; Pinto and Blue, 2015). Overcoming obstacles that disadvantage indigenous businesses through more inclusive and culturally responsive accounting practices is required (Rkein and Norris, 2012). A step towards self-determination in financial reporting is the multiple bottom-line reporting approaches that include measures of economic, social and environmental success (Elkington, 1997; Pinto and Blue, 2015), or quadruple bottom-line reporting that also includes cultural components in additional to economic, social and environmental measures (Scrimgeour and Iremonger, 2004).

We view a systemic transformation of accounting practices as part of the solution; however, financial literacy (e.g. knowledge, confidence in applying this knowledge, other enabling factors) is also required (Blue and Brimble, 2014). With regard to accounting practices, Davie (2000) examined the accounting practices that were imposed on Fijian indigenous people in the nineteenth and mid-twentieth centuries, revealing the explicit assumption about indigenous Fijians' lack of ability to "do accounting" and an implicit assumption about their societal values and beliefs not aligning with Western accounting practices (Davie, 2000). Therefore, rather than make assumptions about financial literacy levels, we agree with Blue (2016) that financial literacy education in indigenous communities 
begins with discussions with community members about what financial skills and knowledge are required. This is particularly important despite evidence showing that First Nation peoples in Australia and Canada currently possess the lowest levels of financial literacy and the lowest socio-economic status within their respective regions (Altman, 2000; Collin, 2011; Thiessen, 2009). The lack of access to financial services in remote and rural localities is also an ongoing issue that First Nation peoples face (Altman and Taylor, 2002; McDonnell and Westbury, 2002). Consequently, there is a pressing need to improve financial literacy levels through context specific knowledge and skill development, and this has been shown to improve the overall economic status of First Nation peoples (Macklin, 2008). We explore the current status of indigenous businesses in Australia in the next section of the paper.

Background - indigenous business in Australia

In Australia, legislation (Aboriginal and Torres Strait Islander Heritage Protection Act 1984 [Cth]) aims to protect the tangible cultural heritage by requiring development proponents to complete the cultural heritage impact assessments, in addition to assessments of social and environmental impacts. The "cultural heritage" industry that has grown because of this legislated requirement and commercial consultants possesses qualifications in archaeology and anthropology, thereby widening the practice area to incorporate theoretical contributions from these disciplines. Despite traditional custodians being the holders of intellectual property over the sites targeted for major developments, the returns awarded to custodians remain minimal (Aston, 2013). While Native Title legislation, such as the Native Title (Queensland) Act 1993, was designed to protect the rights and interests of Australian First Nation peoples by requiring that First Nation claimants be included in the decisionmaking process, the final decision to approve or not approve a development rests with the government.

For more than a decade, the Aboriginal and Torres Strait Islander researchers from a range of disciplines, including economics, business, humanities and law, have focused on identifying factors impacting negatively on the economic status and well-being of Australia's First Nation peoples (Hunter, 2015; Schaper, 1999). Foley (2004) suggested that entrepreneurship was firmly entrenched in Australia's Aboriginal and Torres Strait Islander society through trade and other commercial undertakings long before the arrival of Europeans and the British colonization of our country in the late eighteenth century. The introduction and dominance of the Western legal and economic systems not only eliminated First Nation peoples' traditional economy but also destroyed their social systems. As such, indigenous people remain in the margins with little political and social power and Western dominance continues to flourish (Pinto and Blue, 2017). However, the emergence of "social entrepreneurship" that shifts the focus from profit to social good and quadruples bottomline financial reporting (Scrimgeour and Iremonger, 2004) has lent assistance in transforming some of these financial practices. For example, Dockery (2014) examined the resource industry in the state of Western Australia and determined that there was minimal leverage benefits (in the form of employment) derived from the recent mining boom, despite significant advancements in the legal framework of native title and stated commitments to corporate social responsibility. Furthermore, Rolfe and Windle (2003) found significant difference between indigenous and non-indigenous peoples' values about cultural heritage sites. They found that non-indigenous people did not value high levels of cultural heritage site protection but didvalue some protection(Rolfe and Windle, 2003). This includedmany Aboriginal sites not being recognised as valuable by commercial operators and/or landholders resulting in loss (Rolfe and Windle, 2003). Unlike environmental and social

Sustainable
indigenous
businesses 
PAR

30,1

impacts of developments that are often included in the cost-benefit analysis, Aboriginal cultural heritage sites are not (Rolfe and Windle, 2003).

Other research by Dodson and Smith (2003) suggested that a lack of clarity surrounding First Nation property and resource ownership rights in Australia further complicates the progression of negotiations with developers by custodians who are charged with the responsibility of protecting cultural heritage assets. Moreover, Janke (2009) identified the absence of communal rights for the ownership and control of indigenous cultural heritage (ICH) and indigenous cultural intellectual property (ICIP) in Australia as posing significant barriers to the realisation of tangible, ICH and ICIP assets by traditional custodians. While researchers have long argued that it is just too difficult to construct a meaningful quantitative measure of "heritage" (Hunt and Smith, 2007; Australian Productivity Commission, 2011), we suggest that quadruple bottom-line financial reporting may provide a salient approach in recognising the importance of culture in accounting contexts (Scrimgeour and Iremonger, 2004). International human rights advocates have also been active in pursuing avenues to ensure recognition of cultural heritage assets. For example, activism with the United Nations Education, Scientific and Cultural Organisation (UNESCO) resulted in a declarative statement that the Aboriginal and Torres Strait Islander peoples should be afforded "the right to control, protect and develop their ICIP over their cultural heritage and traditional knowledge". In the lead-up to this declaration, KirshenblattGimblett (2004, p. 60) examined the efficacy of UNESCO policy and standards as instruments for the protection of the intangible ICH assets. She observed UNESCO's policy shift in 2001 from supporting folklore professionals in documenting and archiving materials pertaining to endangered traditions, to a renewed focus on "sustaining the traditions themselves by supporting practitioners". Importantly, Kirshenblatt-Gimblett (2004) recognised that intangible heritage is not only "embodied in the culture bearer" but "is also inseparable from the material and social worlds of persons" (p. 60).

Within the New Zealand context, the accounting treatment of cultural heritage assets was transformed in the 1990s with the universal application (in public benefit and other notfor-profit entities holding heritage cultural and community assets) of private sector financial reporting requirements (based on IFRS and GAAP). However, a mode of accounting that was developed to serve a capitalist economic system of maximising financial returns to private investors remained inconsistent with the overarching purpose of a public sector "whose primary function was to meet social and cultural objectives, not economic goals"' (Wild, 2011, p. 10). In addition, prior research confirmed that the value of intangible assets in the form of intellectual property was often inflated in financial reports as firms approached bankruptcy (Bodle, 2013). Moreover, the tangible ICH assets were generally under- reported because they failed to meet the definition and recognition criteria under current reporting standards (Carnegie and West, 2005; Hunt and Smith, 2007; Wild, 2011). Consequently, we argue that more holistic accounting approaches that hold social, environment and cultural values to be as important as profit (quadruple bottom-line) are more appropriate for the Aboriginal and Torres Strait Islander businesses and could be considered as a critical success factor for future indigenous businesses.

Methodology - a critical evaluation of policy and practice (interdisciplinary/ multidisciplinary)

Our research adopts a framework from various fields, including macro- and micro-economic theory, management theory, change management theory, accounting theory and sustainability theories. Concepts derived from integrating the theories that will advance knowledge in areas of reconceptualism (Nalder and Ganis, 2009; Pinar, 2004; Yang, 2001) 
and indigenous entrepreneurship (Pinto and Blue, 2015, 2017) are discussed below. Reconceptualism involves adopting a First Nation epistemological standpoint in which the deficit model used in the Western paradigm is replaced by a positive relational model that is compatible with First Nation world views. Economic and developmental theorists working from a First Nation paradigm have argued that the mechanisms of non-Aboriginal administrative structures, which are themselves dysfunctional, cannot be assumed to adequately accommodate Aboriginal rights and interests (Altman, 2003). Furthermore, the economic outcomes from the "resource" industries impact negatively on the well-being of the Australian Aboriginal and Torres Strait Islander peoples by damaging what is of most value in their lives. In particular, there has been a tendency in mainstream service delivery approaches to bypass, undermine and de-fund First Nation organisations, which lends further support for the need to address the capacity constraints within and between the governments engaging with the Aboriginal and Torres Strait Islander communities (Dockery, 2010).

Internationally, the Aboriginal and Torres Strait Islander scholars have responded to these issues in arguing for initiatives that target the systemic and structural impediments to the Aboriginal and Torres Strait Islander people's self-efficacy. However, there is some suggestion that there are a plethora of cultural limitations to fully understanding what initiatives are required (Dodson and Smith, 2003, p. 8). Critical Race Theory[1] provides a theoretical foundation for this project as it assists in providing cross-cultural understandings, and upon identifying the fundamental and structural sites of intervention needed to achieve positive change. In particular, interventions need to relate to current governance arrangements including Acts of Parliament pertaining to corporations, and the interpretation of these legal instruments into rules for corporate governance. In the context of this study, we posit that the accounting framework contributes to this as discussedbelow.

As stated previously, indigenous entrepreneurship was firmly entrenched in the Aboriginal and Torres Strait Islander societies through trade and other commercial undertakings long before the arrival of Europeans (Foley, 2004). To better understand the nature of indigenous entrepreneurship, Hindle and Moroz (2010) defined it as activities “ [.. .] focused on new venture creation or the pursuit of economic opportunity, or both for the purpose of diminishing Indigenous disadvantage through culturally viable and community acceptable wealth creation" (p. 372). In this way, it differs from Western definitions of entrepreneurship in which it focuses on reducing the Aboriginal and Torres Strait Islander disadvantage through culturally appropriate ways of acquiring wealth that undoubtedly include respect for intangible heritage values. In the next section of this paper, the importance of intangible heritage, that is, the cultural, economic, environmental and sustainable values, is discussed. We also review and critically evaluate the accounting standards frameworks, and environmental management accounting theories to present commentary on the relative merits of alternative policy directions.

\section{Issues with the accounting standards frameworks - national and international}

Existing accounting frameworks such as that of the Australian Accounting Standards Board (AASB) only permit intangible investments to be recorded in the accounting system as "assets" if the items meet both the asset definition and the recognition criteria (AASB 138, para. 18). The asset definition criteria for intangible assets comprise three primary attributes, namely, identifiability, control and future economic benefits (AASB 138, para. 10). Asset recognition criteria for intangible assets comprise two attributes:
Sustainable indigenous businesses 
PAR

30,1

6

(1) probability that the expected future economic benefits attributable to the assets will flow to the entity; and

(2) the costs associated with the asset can be measured reliably (AASB 138, para. 21).

However, many intangible assets tend to have different economic characteristics from those assets as defined and recognised under the current financial accounting framework and, as a result, are often not included in the balance sheet. More specifically, the three distinguishing economic characteristics of intangible assets, which include inherent uncertainty, partial excludability and non-separability, can render these assets (in many cases) to fall outside of the accepted definitions and recognition criteria.

In considering how traditional custodians derive benefit from the use of ICIP that is vested in the intangible cultural heritage, it is useful to examine how ICIP is treated under current accounting standards. Typically, intellectual property has been viewed as an internally generated intangible asset and represents one of the most controversial areas in the Australian standard setting process as internally generated intangible assets cannot be directly linked to a firm's income stream. Intellectual property exists independently of a product or service, and, therefore, is valuable to a business regardless of the existence of an adequate reporting system. However, profits and losses currently reported by businesses may not adequately reflect the enterprise's economic profitability, particularly if intellectual property is responsible for the success of the business model and/or its business strategy. As intellectual property is not explicitly stated on the balance sheet and investments in creating intellectual property are usually expensed as these occur, both the earnings and the book value of equity are understated by the current accounting models (Canibano et al., 2000; Lev and Zarowin, 1999). Consequently, increases in the cost of capital may result in intellectual property-intensive enterprises (e.g. public access cultural programs) finding increasing difficulty in passing funding hurdles. Furthermore, the management of these enterprises may become more challenging as adequate information on all the assets and liabilities of a company is unavailable.

To further explicate the need for accurate assessment of ICIP in the Aboriginal and Torres Strait Islander enterprises, a recent study by United Nation World Tourism Organisation on Tourism and Intangible Cultural Heritage (2012) identified major challenges for the developers of ICH-based tourism projects, particularly within the context of attending to issues surrounding cultural revival and maintenance. While acknowledging indigenous knowledge holders as stakeholders, the recommendations arising from this study directly inferred that tourism operators were developers of products that used assets and labour of indigenous cultural workers through the medium of a "tourism guide", who needed to be provided training and sufficient remuneration (World Tourism Organisation, 2012). However, no consideration was given to the notion of profit sharing. Rather the model was based on the assumption that tour participants would purchase items made by artists and/or pay to attend performances. This might be advantageous to tour operators who receive payment from each tour customer, whereas the tour customers had the option to "look but not buy" arts, crafts and food items or performance tickets from the First Nation enterprises, which undermines the returns and does not recognise the cost of the service or infrastructure on cultural sites. Thus, there exists a critical need to enable the quantification of purchases relative to visitation, so as to provide the basis for a more equitable economic model.

Intellectual property, when used in tourism contexts, falls within the scope of International Public Sector Accounting Standards that are based on International Financial Reporting Standards. If intellectual property is held and maintained by an enterprise 
principally for its contribution to knowledge and culture, it should be classified as heritage assets because it possesses historic, artistic, scientific, geophysical or environmental qualities (Wild, 2011). However, as suggested earlier, reporting and accounting for ICH assets are often not characterised as assets because these cannot be directly matched to the firm's income stream. Furthermore, heritage assets held by these organisations are more likely to be primarily generating outflows of cash (expenses). Obtaining market valuations for these types of ICH assets represents a costly process and this tends to discourage First Nation organisations from valuing such assets.

Sustainable indigenous businesses

Issues with the environmental management accounting - theories and practices

Effective financial management incorporating contextual awareness is critical to a firm's viability and ongoing survival. Economic downturns such as the global financial crisis highlighting deficiencies in current financial management practices have increased demand for ethical investment opportunities. The profession's response to the rise in demand for ethical investment opportunities has been the introduction of environmental management accounting where accountants advocate the use of accountability measures such as the balanced scorecard (BSC), life cycle analysis (that provides measurement and reporting mechanisms that highlight outcomes in this regard and thus influences management behaviour), ecosystems service and contingency valuation method (Morrison and Brown, 2009). Interestingly, a report by Jackson (2009) details how societies find it difficult to accommodate aspirational goals for a sustainable economy as accepted measures of economic growth are explicitly built around consumption and gross domestic product (GDP) growth. However, current conceptualisations and measurement of GDP are inadequate, as these do not properly account for changes in the asset base. In particular, current measures of gross fixed capital investment do not account for depreciation of capital stocks (for example, degradation natural resources). Accordingly, Jackson (2009) suggested the need for a new vision of governance to ameliorate deficiencies in current neoclassical economics. Moreover, researchers in both Australia and New Zealand have raised concerns about the current gaps in management accounting in which intangible assets in the form of ICIP and

AQ: 5 ICH. They argue that these types of assets are not adequately accounted for, and culturally located values and measures (which are of significance in the First Nation enterprises) are not considered in the BSC (Elijido-Ten and Tjan, 2011; O'Connor and Feng, 2005). This oversight could largely be attributed to prevailing conditions whereby ICH and ICIP assets contravene fundamental accounting requirements that endorse the reporting of information that should reflect qualitative characteristics of "consistency", "comparability" and "verifiability" to be of any use to stakeholders (AASB, 1990).

In relation to the BSC, it incorporates both environmental and social measures; environmental management accounting is also concerned with environmental impacts of organisations and how to best measure such negative and positive impacts in monetary terms. Kaval (2011) and Preston (2013) investigated the existing methodologies most commonly used to measure organisations' ecological impact. The most commonly used measurement tools and valuation methods reported in the literature include the contingent valuation method (Morrison and Brown, 2009; Ellwood and Greenwood, 2015), life cycle AQ: 6 analysis, ecosystem service, the BSC and environmental management accounting systems, to name a few (see appendix in Preston, 2013). These results demonstrate recent increases in stakeholder demands for firms to be accountable for costs associated with adverse economic and social impacts on business and society values.

Recent research has sought to investigate issues pertaining to the growth in stakeholder demands for greater corporate responsibility together with elevating levels of criticism 
PAR

30,1

levied towards companies operating in industries producing deleterious social or environmental impacts (e.g. mining, construction and manufacturing, to name a few). In particular, Black (2013) devised a management framework and a set of tools under the premise of "a social license to operate", which encompass a stakeholder engagement strategy, directed towards assisting them in navigating complex sociopolitical environments. Black (2013) argued that a social license to operate must be "earned" via consideration of "mov[ing] beyond community benefits and invest[ing] in regional development". Such a "participatory governance" structure is argued to be essential in minimising the negative environmental and social consequences attached to company activities. In the following section, we review policy alternatives aimed at supporting the legitimacy and management of ICH and ICIP First Nation enterprises.

\section{Issues with the exploration of policy alternatives}

Numerous productivity investigations worldwide have directly linked the absence of an economic basis in the First Nation communities to low performance on health and well-being indicators (Wild, 2011). However, Bourke (1998) argued that the Aboriginal and Torres Strait Islander people have always had an economic basis that differs somewhat from the Western neoliberal economic principles. Moreover, from a public policy perspective, the Australian Government has emphasised a need for government agencies, private sector enterprises, indigenous enterprises and First Nation communities to open a dialogue so as to "foster business to business transactions and commercial partnerships.. .[and] [integrate] Indigenous business into the Australian economy" (Hunter, 2015, p. 8). However, it is often based on the central assumption that First Nation peoples constitute a homogenous community, which is unrealistic or (as reported by UNESCO) a "rarity in life" (Corporate Analysis Enhanced Responsibility, 2013). Thus, First Nation peoples' capacity (for instance) to negotiate a fair distribution of economic revenues from resource extraction remains contingent upon the existence of measures, pricing structures and use of protocols tailored for communally held ICH and ICIP assets. To date, existing protocols used for negotiations for the protection of First Nation cultural heritage was through government legislation (Aboriginal Heritage Act, 1988); however, this has generally proved ineffective (O'Faircheallaigh, 2008, p. 25). This is mainly due to the weak bargaining position of the First Nations peoples because of the lack of commercial and financial literacy skills and also the disparity between the measurements of values placed on intangible and tangible cultural heritage assets (O'Faircheallaigh, 2008, p. 27).

A holistic approach to conceptualising a rigorous economic model that incorporates appropriate accounting tools is desperately required to effectively manage risks associated with the negative impact on the legitimacy, sustainability and survival of enterprises, as well as to address the lack of transparency in financial management and poor governance skills. Such a model must be capable of accommodating the complexity of ICH and ICIP asset-based enterprises in a transparent manner, so as to provide a means to protect, preserve and use First Nation peoples' most important assets (i.e. lands, water, culture and heritage). In the next section, a new perspective of measuring the value of ICH assets is presented.

Recommendations - a new perspective of indigenous cultural heritage asset value

In situations where ICH assets remain unaccounted for, there is a high probability that these assets are underpriced in business negotiations conducted by enterprises. What distinguishes the First Nation enterprises acquisition and management of ICH assets is the 
impact of communal ownership, which involves extensive (protocol-bound and valuesbound) negotiation. However, to date, these distinctive circumstances have not been a consideration in the reporting requirements of ORIC. Wild (2011, 2013) provided some direction towards incorporating cultural values in ICH asset valuation in recognition that cultural values could have utility in the development of tools for measuring collectively held intangible culture and heritage asset value in services that are aimed at social development and well-being. This framework developed for a museum comprised a set of fundamental qualitative characteristics (such as relevance, faithful representation, comparability and verifiability) for accounting information to be useful to its users (cited in Wild, 2011, p. 7).

To address this shortfall in theory and practice in an Australian context, a holistic approach to policy formulation is required that integrates economic, cultural, social, environmental and financial management theories, so as to support the development of standards, tools, measures and indicators that adequately enable recognition of ICIP in financial accounting. Moreover, such an approach needs to embed the values of First Nation peoples if the financial reporting methods are to be both accurate and usable. One such approach that could be used is the total impact measurement and management (TIMM) developed by PricewaterhouseCoopers that incorporates framework and tools for assessing social and socio-economic impacts, such as cultural heritage.

\section{Embedding the values of First Nation people in financial reporting through indigenist methodological approaches}

The methodology advocated for research with First Nation peoples is known by the term, "indigenist", which was proposed by Rigney (1997). An indigenist research methodology is underpinned by CRT, predominant in the North American literature, which "focuses on and learns from the array of cultural knowledge, skills, abilities and contacts possessed by socially marginalised groups that often go unrecognised and unacknowledged" (Yosso, 2005). Indigenist research is distinguished by its revisionist intent, and this evolving framework incorporates Aboriginal post-colonialism and de-colonising strategies developed through dialogue between indigenous peoples in a global forum. Martin and Mirraboopa (2003) listed its main features as incorporating recognition of First Nation peoples' worldviews, knowledge and realities as distinctive and vital to the existence and survival of the First Nation communities. Such an approach honours Aboriginal social mores as essential processes through which First Nation peoples live, learn and situate themselves as Aboriginal people in their lands and those lands of other Aboriginal people. Hence, this approach emphasises the social, historical and political contexts that serve to shape experiences, lives, positions and futures of First Nation people. Moreover, this methodology privileges the voices and experiences of Aboriginal people and focuses on identifying and redressing issues of importance attached to First Nation peoples.

Central to this approach is the acknowledgement that communication arises from respectful communication with the First Nation peoples of Australia, that is, the Aboriginal and Torres Strait Islander peoples (Lui, 1998). Moreover, a localised approach that acknowledges the specific historical facts and experiences of individual communities of colonisation (Smith, 1999) forms the basis of ethical research. To ensure that any research is theoretically and conceptually grounded in the authority of the traditional owner/custodians as local knowledge holders, a participatory action research model is recommended. Participatory action research provides for the establishment of mutually beneficial partnerships in which participants (including the researchers) work together to achieve the set research goals. In the context of this research, the outcomes pertained to the identification of tools (for subsequent testing) to assist in the accounting treatment of ICIP as 
PAR

30,1

an intangible asset within an Australian regulatory environment. More specifically, the goal would be to define an auditing process and accountability model incorporating cultural and social as well as environmental measures in consultation with local community elders[2].

\section{Embedding the values of First Nation people in financial reporting through tailored financial} literacy education

A key element of this model relates to the existing levels of personal and commercial

financial literacy in the First Nation participant cohorts. In terms of financial literacy, we refer to a comprehensive model (as per Blue and Brimble, 2014) that extends beyond the basic financial knowledge to include enabling factors (literacy, numeracy and digital literacy) and behavioural elements (confidence and motivation to apply knowledge). Collectively, these factors promote informed participation and effective decision-making and may promulgate more sustainable outcomes through a structured, inclusive and integrated education program that represents a key element of the proposed framework. Importantly, such a framework needs to circumvent conventional financial literacy education approaches that focus on individual wealth accumulation so as to incorporate measures of collective well-being and how financial decision-making affects communities (Blue, 2016; Blue et al., 2015; Lucey et al., 2015).

\section{Embedding the values of First Nation people in financial reporting through a case study approach}

Elders participating in the research designed a case study using the indigenist methodology mainly to identify and redress the central issue in this research. In other words, to find out their expectations in regard to returns provided to the Aboriginal and Torres Strait Islander communities from the users of intangible and tangible cultural heritage assets across a range of local industries, including mining, tourism, fishing and education (Harward-Nalder and Grenfell, 2012; Jaszi, 2010). Early results from the case study that have informed this subsequent discussion are relevant themes identified by elders involved in rich descriptions of the local context and perceptions of how cultural heritage matters influence the management and growth of corporations that are regulated by the ORIC (Stevenson, 1996; Morley, 2015). By conducting case studies of newly registered enterprises, intangible ICH and ICIP assets should offer a quantifiable value using the environmental management accounting, by adapting the BSC to include social and cultural values (Kaplan and Norton, 2004). This should be of interest and importance to economic and social development planners and policymakers, institutions and industry operators/suppliers that are dependent on local cultural products and services. Such perceptions should enable firms more success in attracting independent external funding at reduced rates of interest.

\section{Embedding the values of First Nation people in financial reporting through recognizing intangible heritage -cultural, economic, environmental and sustainability values}

First Nation peoples' epistemologies are closely aligned with living systems theory. This means for First Nation peoples, cultural heritage comprises in the main intangible assets, for example, knowledge about non-agricultural food sources, the medicinal qualities of natural vegetation and about ecosystems management (Harward-Nalder and Grenfell, 2012). In contemporary indigenous thought, the creation of scientific research institutes, restored sites, heritage trails and cultural heritage enterprise has become a meta-cultural phenomenon in its own right that inextricably links the intangible with tangible. Intangible 
heritage is not only "embodied" in the culture bearer but also "inseparable from the material and social worlds of persons" (Kirshenblatt-Gimblett, 2004, p. 61).

In modern economic terms, cultural heritage can be thought as "labour" over time that contributes services and goods that do not deplete or degrade natural resources. While Australia adopted the Declaration on the Rights of Indigenous People in 2009, instruments for the recognition and protection of collectively held intangible ICH assets do not currently exist. Furthermore, ICIP laws neither protect the communal rights of indigenous peoples nor allow for protection in perpetuity.

The accounting treatment of ICH and ICIP are both difficult to measure and implement. Indeed, both public and private sector corporations find it difficult to define, recognise or measure heritage assets because no single standard exists to provide such guidance. This is further exacerbated when heritage assets that include intellectual property belong to the First Nation enterprises where, as discussed above, intellectual property has been viewed as an internally generated intangible asset, does not meet asset definition and recognition criteria and is one of the more controversial areas in Australian accounting standards. Furthermore, intellectual property exists independently of a product or service, and, therefore, is valuable to a business whether or not an adequate reporting system exists. Intellectual property-intensive enterprises relying on indigenous cultural knowledge for entertainment, guiding or hospitality services to the tourism industry may find it even more difficult to pass the funding hurdle. In addition, the financial information provided does not give a complete and faithful representation of a FNSE's holdings of ICH or ICIP assets. Thus, management of these enterprises becomes a much greater challenge because adequate information on all the assets and liabilities of a company is not available (Bodle and Nalder, 2013).

\section{Embedding the values of First Nation people in financial reporting through the social responsibility element of corporateperformance}

The stakeholder approach to corporate sustainability takes into account the multi-fiduciary obligations of corporations by recognising that their responsibilities go beyond the shareholder-management relationship (Goodpaster and Matthews, 2001). By having enabled and empowered employees achieving organisational environmental outcomes through community-driven (balancing stakeholders needs) and synergy-driven approaches aimed at enabling a "win-win" for all three aspects of people, profit and planet (Van der Woerd and Van den Brink, 2004) progress in an equitable direction is possible. However, there is a need to identify discrete responsibilities of an organisation as different stakeholder groups could evaluate organisational performance in different ways (Chen et al., 2008). Both the stakeholder theory and the legitimacy theory have been linked to performance on a corporate level, whereas organisation commitment by employees and employee empowerment relates to employee motivation toward achieving organisational environmental performance. These theories (together with goal congruency motivators for employees) form the basis for the application of environmental management accounting, social/sustainability BSC or contingency valuation methods for the Aboriginal and Torres Strait Islander corporations.

\section{Embedding the values of First Nation people in financial reporting through environmental management accounting \\ Finally, environmental management accounting could be used by the First Nation enterprises in assessing and managing their sustainability performance by quantifying environmental impacts through the use of performance metrics, such as costs, benefits, risks}

Sustainable indigenous businesses 
PAR

30,1

12

and opportunities related to current sustainability management practices. At the same time, new knowledge gained in this context may have transferability to other environmental management accounting initiatives. Despite the existence of United Nations Declarations (for example, The Mataatua Declaration), which "insist that the beneficiaries of Indigenous knowledge (cultural and ICIP rights) must be the direct Indigenous descendants of such knowledge" (United Nations Commission on Human Rights, 1993), there is a relative absence of applied research addressing problems associated with the wealth generated from ICH and ICIP assets that invariably flows to the private sector. As a result, there is less of an incentive for non-indigenous corporations to deliver a fair return on profits derived from ICH and ICIP assets to the traditional knowledge holders.

\section{Embedding the values of First Nation people in financial reporting through adopting the proposed framework}

The first approach is to devise a set of cultural, rather than economic, values for measuring the culture and heritage asset value, such as that in the well-being of communities' reporting framework discussed in the study by Wild (2011, p. 7). These cultural values will have utility in the development of tools for measuring collectively held intangible Aboriginal and Torres Strait Islander culture and heritage asset value in the First Nation enterprises aimed at social development and well-being. We stress, however, that long-term development of the financial and commercial knowledge, skills and confidence of the First Nation communities is important to support the process of adopting, embedding and sustaining this framework. The details of how to achieve this goal are, however, illusive as further research into First Nation financial and, in particular, commercial literacy is needed to inform the strategies in this regard. A second approach is Preston's (2013) TIMM frameworks and tools for assessing social and socio-economic impacts, such as the intangible culture and heritage asset values, on the First Nation enterprises and the values of the wider Australian indigenous societies/communities.

\section{Conclusion}

Critical success factors for sustainable indigenous business identified in this paper include social and economic measures to value indigenous knowledge, ICH and ICIP in business contexts. We suggest that this will enhance the accounting reporting system in Australia and appropriately deal with the value of these items pursuant to the critical race theory. Both financial and commercial literacy skills are also required to assist in reducing and (hopefully) preventing exploitation of indigenous tangible and intangible assets. However, the low number of Aboriginal and Torres Strait Islander people working in accounting roles remains a concern and will continue to have an impact on who controls funding (Lombardi and Cooper, 2015). In this paper, we identified multiple areas to embed the values of First Nation people in financial reporting practices to improve practice and inclusion. We support Dockery's (2010) proposition that culture and heritage should be viewed as part of the solution to the problem of socio-economic disadvantage and argue that augmented accounting, accountability and auditing approaches are required. In the context of accounting, having elders assist in valuing these assets will enable a fairer price to be determined, which in turn, would lead to more equitable payments for services and/or royalties. The process of arranging for payment for Aboriginal participation in the Teaching from Country program: 
Exposed some of the unusual ways that Aboriginal people and University people think about money, probity and value, and reminds us of how far we have yet to go in the work of valuing Indigenous knowledge (Christie, 2010, p. 64).

With accountability, non-indigenous organisations will have to be accountable to the elders, First Nation businesses and Aboriginal and Torres Strait Islander communities to ensure the methods adopted are culturally appropriate. With regard to auditing practice, elders, First Nation businesses and Aboriginal and Torres Strait Islander communities may wish to adopt auditing roles so as to monitor whether Western organisations and government bodies are consulting and acting in their best interests (Lombardi and Cooper, 2015; Rkein and Norris, 2012). Finally, a central theme arising from this research was the need to measure both financial and commercial literacy competencies as these skills play a critical role in the future sustainability and success of indigenous businesses. Further research in this area is required to identify equitable measures and thus, ensure indigenous businesses have a "measurable" chance at success.

\section{Notes}

1. A critical examination of society and culture where the race, law and power intersect. It recognises that racism is engrained in the fabric and system of society and thus demands an interdisciplinary approach.

2. Internationally, indigenous cultural intellectual property (ICIP) is encompassed in the UNESCO Convention for the Safeguarding of Intangible Cultural Heritage (2003) where it is defined as "the practices, representations, expressions, knowledge, skills - as well as the instruments, objects, artefacts and cultural spaces associated therewith - that communities, groups and, in some cases, individuals, recognise as part of their cultural heritage" (cited in World Tourism Organisation, 2012). In Article 31, (Australian Human Rights Commission 2009) presented a declaration of the UN General Assembly of 2007.

\section{References}

Altman, J.C. (2000), “The economic status of Indigenous Australians", Discussion Paper No 193/2000, ANU, Canberra.

Altman, J.C. (2003), "People on country, healthy landscapes and sustainable indigenous economic of the Arnhem land case: the drawing board", An Australian Review of Public Affairs, Vol. 4 No. 2, pp. 65-82.

Altman, J. and Taylor, J. (2002), "Submission to the parliamentary joint committee on corporations and financial services inquiry into the level of banking and financial services in rural, regional and remote areas of Australia' Regional and Remote Areas of Australia", CAEPR, ANU, Canberra.

Aston, H. (2013), "How the Uluru resort deal went bad news, rock and a hard place: the largest single evaporation of public monies in the indigenous policy domain ever", Age.

Australian Accounting Standards Board (AASB) (1990), Statement of Accounting Concept (SAC) 2: Objective of General Purpose Financial Reporting SAC 2, Australian Accounting Research Foundation, Caulfield.

Australian Human Rights Commission (2009), United Nations Declaration on the Rights of Indigenous People, Australian Human Rights Commission, Sydney, available at: www.humanrights.gov.au/ publications/un-declaration-rights-indigenous-peoples-1

Australian Productivity Commission (2011), "Overcoming indigenous disadvantage: key indicators 2011", Fact Sheet Indigenous Men and Women, Commonwealth of Australia, Canberra, 
PAR 30,1 available at: www.pc.gov.au/data/assets/pdf_file/0014/111614/key-indicators-2011-factsheetmen-women.pdf

Battiste, M.A. (2013), Decolonizing Education: Nourishing the Learning Spirit, Purich, Saskatoon, SK.

Black, L. (2013), “The social licence as a framework for managing cumulative impacts: a case study of the upper hunter mining dialogue", paper presented at the Proceedings of the International Association of Impact Assessment Annual Conference, Calgary.

Blue, L.E. (2016), "Exploring the financial literacy education practices in a Canadian Aboriginal Community: a case study", PhD dissertation, Griffith University.

Blue, L.E. and Brimble, M.A. (2014), "Reframing the expectations of financial literacy education: Bringing back the reality", JASSA the FINSIA Journal of Applied Finance, Vol. 1, pp. 37-42.

Blue, L.E., Grootenboer, P. and Brimble, M.A. (2015), "The importance of praxis in financial literacy education: an indigenous perspective", paper presented at the Proceedings of the 38th Annual Conference of the Mathematics Education Research Group of Australasia, Brisbane.

Bodle, K.A. (2013), "The effects of non-restrictive accounting practices for intangible assets on financial ratios: consequences for bankruptcy prediction models", doctor of philosophy, Griffith University, UniPrint.

Bodle, K.A. and Nalder, G. (2013), "Adapting environmental management accounting processes and the balance scorecard to meet performance reporting requirements in first nation social enterprises: a feasibility study", paper presented at the Environmental Management Accounting Network (EMAN) Global 2013 Conference, Gold Coast.

Bourke, C. (1998), "Economics: independence of welfare", in Bourke, C., Bourke, E. and Edwards, B. (Eds), 2nd ed., University of Queensland Press, Queensland, pp. 219-244.

Brayboy, B.M.J. (2005), "Toward a tribal critical race theory in education”, The Urban Review, Vol. 37 No. 5, pp. 425-446.

Buhr, N. (2011), "Indigenous peoples in the accounting literature: time for a plot change and some Canadian suggestions", Accounting History, Vol. 16 No. 2, pp. 139-160.

Canibano, L., Garcia-Ayuso, M. and Sanchez, P. (2000), "Accounting for intangibles: a literature review", Journal of Accounting Literature, Vol. 19, pp. 102-130.

Carnegie, G.D. and West, B.P. (2005), "Making accounting accountable in the public sector", Critical Perspectives on Accounting, Vol. 16 No. 7, pp. 905-928.

Chen, J., Patten, D. and Roberts, R. (2008), “Corporate charitable contributions: a corporate social performance or legitimacy strategy?", Journal of Business Ethics, Vol. 82 No. 1, pp. 131-144.

Christie, M. (2010), "Money matters: payment for the participation of Aboriginal knowledge", Journal of Learning in Social Contexts - Teaching from Country, Vol. 2, pp. 60-66.

Collin, D. (2011), Aboriginal Financial Literacy in Canada: Issues and Directions, Task Force on Financial Literacy, Waterstone.

Corporate Analysis Enhanced Responsibility (2013), "A benchmark report on responsible investment in ATSIC (1999)", paper presented at the UNESCO/Smithsonian Conference, Turin, available at: www.responsibleinvestment.org/wp-content/uploads/2013/07/2013Benchmark-Report.pdf

Davie, S. (2000), "Accounting for imperialism: a case of British-imposed indigenous collaboration", Accounting, Auditing \& Accountability Journal, Vol. 13 No. 3, pp. 330-359.

Dockery, A.M. (2010), "Culture and wellbeing: the case of indigenous Australians", Social Indicators Research Journal, Vol. 99 No. 2, pp. 315-332.

Dockery, A.M.(2014), "Resourcecurse orcure?”, CSR, Sustainability, Ethics E Governance, pp. 75-89.

Dodson, M. and Smith, D.E. (2003), Governance for Sustainable Development: Strategic Issues and Principles for Indigenous Australian Communities, ANU, Canberra. 
Elijido-Ten, E.O. and Tjan, Y. (2011), "Sustainability balanced scorecard disclosures: an Australian investigation centre for social and environmental accounting research", paper presented at the CSEAR, 2011: Australasian Conference.

Elkington, J.(1997), Cannibals with Forks: The Triple Bottom Line of 21st Century, Capstone, London.

Ellwood, S. and Greenwood, M. (2015), "Accounting for heritage assets: does measuring economic value 'kill the cat'?", Critical Perspectives on Accounting, Vol. 38, pp. 1-16.

Foley, D. (2004), "Understanding indigenous entrepreneurship: a case study analysis", doctor of philosophy, University of Queensland, Queensland.

Gallhofer, S., Gibson, K., Haslam, J., McNicholas, P. and Takiari, B. (2000), "Developing environmental accounting: insights from indigenous cultures", Accounting, Auditing \& Accountability Journal, Vol. 13 No. 3, pp. 256-267.

Goodpaster, K.E. and Matthews, J.B. (2001), “Can a corporation have a conscience?”, Business Ethics: Readings and Cases in Corporate Morality, 3rd ed., McGraw- Hill, New York, NY.

Harward-Nalder, G. and Grenfell, M. (2012), "Learning from the Quandamooka", in Arthington, A.H., et al. (Eds), A Place of Sandhills: Ecology, Hydrogeomorphology and Management of Queensland's Dune Islands, paper presented at the Proceedings of the Royal Society of Queensland, Vol. 117, pp. 495-501.

Hindle, K. and Moroz, P. (2010), "Indigenous entrepreneurship as a research field: developing a definitional framework from the emerging canon", International Entrepreneurship and Management Journal, Vol. 6 No. 4, pp. 357-385.

Hunt, J. and Smith, D.E. (2007), "Indigenous community governance project: year two research findings", CAEPR Working Paper No 36/2007, The Australian National University.

Hunter, B. (2015), "Whose business is it to employ indigenous workers?", The Economic and Labour Relations Review, Vol. 26 No. 4, pp. 631-651.

AQ: 10

Jackson, T. (2009), "Prosperity without growth? Transition to a sustainable economy", in Commissioner, E. (Ed.), Sustainable Development Commission.

Janke, T.(2009), Beyond Guarding Ground:A Visionfora National Indigenous Cultural Authority, Terri Janke \& Co, Roseberry.

Jaszi, P.A. (2010), "Traditional culture: a step forward for protection in Indonesia", Ford Foundation, May.

Kaplan, R.S. and Norton, D.P. (2004), "Measuring strategic readiness of intangible assets", Harvard Business Review, pp. 52-63.

Kaval, P. (2011), Measuring and Valuing Environmental Impacts: A Systematic Review of Existing Methodologies, University of Waikato, Network for Business Sustainability, Waikato, NZ.

Kirshenblatt-Gimblett, B. (2004), "Intangible heritage as metacultural production", Museum International, Vol. 56 Nos 1/2, pp. 52-65.

Lev, B. and Zarowin, P. (1999), "The boundaries of financial reporting and how to extend them", Journal of Accounting Research, Vol. 37 No. 1, pp. 353-385.

Lucey, T.A., Agnello, M.F. and Laney, J.D. (2015), The Nature of Financial Literacy a Critically Compassionate Approach to Financial Literacy, Springer, pp. 1-20.

Lui, G. (1998), "Mina Mir Lo Ailan Mun [Good talk for Torres Strait Islanders]: proper communication with Torres Strait Islander peoples", available at: www.Atsip.Qld.Gov.Au/EverybodysBusiness/Protocols-Torres-Straitislander/documents/minamir.pdf

McDonnell, S. and Westbury, N. (2002), "Banking on Indigenous communities: issues, options, and Australian and international best practice", Working Paper 18/2002, Centre for Aboriginal Economic Policy Research (CAEPR), Australian National University.

Macklin, J. (2008), Closing the Gap Between Indigenous and non-Indigenous Australians, Commonwealth of Australia.
Sustainable indigenous businesses 
PAR 30,1

Martin, K. and Mirraboopa, B. (2003), "Ways of knowing, being and doing: a theoretical framework and methods for indigenous and indigenist research", Journal of Australian Studies, Vol. 27 No. 76, pp. 203-214.

Morley, S.R. (2015), What Works in Effective Indigenous Community-managed Programs and Organisations?, Australian Institute of Family Studies, Melbourne.

Morrison, M. and Brown, T. (2009), "Testing the effectiveness of certainty scales, cheap talk, and dissonance-minimization in reducing hypothetical bias in contingent valuation studies", Environmental and Resource Economics, Vol. 44 No. 3, pp. 307-326.

Nalder, G. and Ganis, V. (2009), "Artist-teacher practitioner research with indigenous Australian communities on sites of conflict and contestation", Australian Art Education, Vol. 32 No. 2, pp. 17-26.

O'Connor, N.G. and Feng, E. (2005), "Using the balanced scorecard to manage intangible assets in a Sino-foreign joint venture", Australian Accounting Review, Vol. 15 No. 2, p. 22.

O'Faircheallaigh, C. (2008), "Negotiating cultural heritage? Aboriginal-mining company agreements in Australia", Development and Change, Vol. 39 No. 1, pp. 25-51.

Pinar, W.F. (2004), "The reconceptualization of curriculum studies", in Flinders, D.J. and Thornton, S.J. (Eds), The Curriculum Studies Reader, 2nded., Routledge Falmer, New York, NY, pp. 149-157.

Pinto, L.E. and Blue, L.E. (2015), "Pushing the entrepreneurial prodigy: Canadian Aboriginal entrepreneurship education initiatives", Critical Studies in Education.

Pinto, L.E. and Blue, L. (2017), “Aboriginal entrepreneurship financing in Canada: Walking the fine line between self-determination and colonization", Journal of Entrepreneurship in Emerging Economies, Vol. 9 No. 1.

Preston, M. (2013), "Measuring and managing total impact: a new language for business decisions", in Partner \& Global Sustainability Leader, P.U (Ed.), More London Riverside, PricewaterhouseCoopers LLP, London.

Rigney, L. (1997), "Internationalisation of an Indigenous anti-colonial cultural critique of research methodologies: a guide to Indigenist research methodology and its principles", paper presented at the HERDSA Annual International Conference Proceedings, Research and Development in Higher Education: Advancing International Perspectives, Vol. 20, pp. 629-636.

Rkein, H.I. and Norris, G. (2012), "Barriers to accounting: Australian indigenous students' experience", Social and Environmental Accountability Journal, Vol. 32 No. 2, pp. 95-107.

Rolfe, J. and Windle, J. (2003), "Valuing the protection of Aboriginal cultural heritage sites", Economic Record, Vol. 79, pp. S85-S95.

Schaper, M. (1999), “Australia's Aboriginal small business owners: challenges for the future", Journal of Small Business Management, Vol. 37 No. 3, pp. 88-93.

Scrimgeour, F. and Iremonger, C. (2004), Maori Sustainable Economic Development in New Zealand: Indigenous Practices for the Quadruple Bottom Line, University of Waikato, Hamilton.

Stevenson, M.G. (1996), "Indigenous knowledge in environment assessment”, Arctic, Vol. 49 No. 3 , pp. 278-291.

Swansson, J. (2010), Analysing Key Characteristics in Indigenous Corporate Failure, Office of the Registrar of Indigenous Corporations, Australian Government, Woden, ACT, pp. 1-85.

Thiessen, V. (2009), "The pursuit of postsecondary education: a comparison of First Nations, African, Asian, and European Canadian youth", Canadian Review of Sociology/Revue Canadienne De Sociologie, Vol. 46 No. 1, pp. 5-37.

United Nations Commission on Human Rights (1993), "The Mataatua declaration on cultural and intellectual property rights of indigenous peoples", paper presented at the First International Conference on the Cultural \& Intellectual Property Rights of Indigenous Peoples, Whakatana, Aotearoa. 
Van der Woerd, F. and Van den Brink, T. (2004), "Feasibility of a responsive business scorecard: a pilot study", Journal of Business Ethics, Vol. 55 No. 2, pp. 173-186.

Wild, S. (2011), "Accounting for heritage, cultural and community assets: an alternative metrics from a New Zealand Maori educational institution", Australasian Accounting, Business and Finance Journal, Vol. 7 No. 1, pp. 3-22.

World Tourism Organisation (2012), Tourism and Intangible Cultural Heritage, UNWTO, Madrid.

Yang, O.S. (2001), "An epistemological and ethical categorization of perspectives on early childhood curriculum", International Journal of Early Childhood, Vol. 33 No. 1, pp. 1-8.

Yosso, T.J. (2005), "Whose culture has Capital? A critical race theory discussion of community cultural wealth", Race Ethnicity and Education, Vol. 8 No. 1, pp. 69-91.

Further reading

ANZ (2011), Adult Financial Literacy in Australia, Australia and New Zealand Banking Group, Melbourne.

Foley, G. (1999), "ATSIC: flaws in the machine”, available at: www.kooriweb.org/foley/essays/essay4. html (accessed January 2014).

Lev, B. (2001), Intangibles: Management, Measurement and Reporting, Brooks Institution Press, Washington, DC.

Maignan, I. and Ferrell, O.C. (2004), "Corporate social responsibility and marketing: an integrative framework", Journal of the Academy of Marketing Science, Vol. 32 No. 1, pp. 3-19.

Wesley, A. and MacCallum, D. (2014), The Political Economy of Corporate Social Responsibility in the Resource Sector in Western Australia: A Case Study of the Proposed James Price Point LNG Precinct Resource Curse or Cure?, Springer, pp. 59-73.

Corresponding author

Kerry Bodle can be contacted at: k.bodle@griffith.edu.au

For instructions on how to order reprints of this article, please visit our website:

www.emeraldgrouppublishing.com/licensing/reprints.htm

Or contact us for further details: permissions@emeraldinsight.com

Sustainable indigenous businesses 